\title{
Internationalization of Higher Education Institutions: The Case of Four HEIs in the Philippines
}

\author{
MA. FLORECILLA C. CINCHES \\ ORCID No. 0000-0001-7205-7733 \\ maflorcortescinches@gmail.com \\ Liceo de Cagayan University \\ Cagayan de Oro City, Philippines \\ RUTH LOVE V. RUSSELL \\ ORCID No. 0000-0002-6585-7916 \\ rrussell@xu.edu.ph \\ Xavier University-Ateneo de Cagayan \\ Cagayan de Oro City, Philippines \\ MARIA LOIDA FAYE C. BORBON \\ ORCID No. 0000-0003-0385-4629 \\ loidsborbon@gmail.com \\ La Salle Green Hills \\ Metro Manila, Philippines \\ JUDITH C. CHAVEZ \\ ORCID No. 0000-0003-2082-3015 \\ jchavez302003@yahoo.com \\ Lourdes College \\ Cagayan de Oro City, Philippines
}

\begin{abstract}
The last decades saw universities from all over the world experiencing increased pressure from the external environments because of globalization. It is a common understanding that internationalization is an institution's ready response and/ or a reaction "to cope with the global academic environment" (Bernardo, 2003; Altbach and Knight, 2007). Many Higher Education Institutions' (HEI) leaders in the Philippines like their international counterparts internationalize their institutions. This paper studied internationalization in four
\end{abstract}


selected HEIs in the country. It reviewed their internationalization practices and /or approaches and its impact to faculty and students. The mixed method design through the case study approach was utilized where each HEI represented a case of internationalization in their respective institution. An interview guide on internationalization adapted from Hill and Green (2008) provided mainly the qualitative information; most quantitative data were taken from Student and Faculty Survey Questionnaire on Internationalization (Iuspa, 2010). Data were also gathered from document analysis. Findings of the study revealed that HEIs in the study varied in their range of internationalization practices, but intentions to internationalize were commonly academic and economic. Attitude of faculty and students toward internationalization was generally positive. However, there were some observed gaps that need to be addressed especially in maximizing faculty members' and students' opportunities for internationalization. Result of this study can offer the HEIs' decision makers valuable information about their respective internationalization processes to guide them further in their strategic planning specifically in sustaining the thrust on internationalization.

Keywords: Globalization, internationalization motives, internationalization approaches, internationalization processes

\section{INTRODUCTION}

The last two decades saw universities from all over the world experiencing increased pressure from the external environments because of globalization. This globalized pressure is recognized as forces acting on educational institutions which are tied to culture, economics, politics, business and power "pushing 21st century higher education toward greater international involvement" (Altbach and Knight, 2007; Bond, 2006). It is an irreversible reality of contemporary human life and its impact has seeped into the educational sector in many complex and paradoxical ways and has challenged traditional institutions (Tullao, 2003). Higher education institutions (HEIs) engage in a variety of international initiatives in response to this growing globalized village and have launched into several approaches to become global educational institutions. Scholars and experts regard the process of internationalization as a prompt response to the widespread phenomenon of globalization (Altbach and Knight, 2007; Chan and Dimmok, 2008; de Wit, 2009; Knight, 2004; Ninomiya et al., 2009). It is a "natural and inevitable consequence of the continued globalization of economies" 
and a response inclusive of policies and practices embarked by academic systems and institutions and even individuals and the purpose is "to cope with the global academic environment" (Bernardo, 2003; Altbach and Knight, 2007).

Additionally, internationalization of higher education institutions is a growing focus of many studies. Other than being a subject of interest to academic institutions, policymakers are now paying attention to this phenomenon because economic performance is affected by the growing cross-border flows of knowledge, knowledge-workers, and students (OECD, 2008; Pama, 2013). In the Philippines, the Commission on Higher Education (CHED) has similarly recognized the need for internationalization as it gears up to support significant researches on this innovation considering the thousands of HEIs comprising both state and private institutions. CHED's mandates include enhancement of institutional quality assurance and directs all HEIs to institute the necessary mechanisms that ensure graduates can competently cope with the standards of a rapidly changing globalized world and be mindful of global competitiveness (CMO 46, s. 2012, art. 1, sec. 2). The internationalization of higher education is not only an internal requirement in the country, it is also seen as a strong component for economic development.

There is a dearth of studies conducted on the internationalization processes in the country. The value of this study lies primarily on assessing what potential of the observed processes in the involved HEIs' internationalization activities can offer in higher education. An in-depth understanding of internationalization is essential for management to sustain the internationalization effort. Findings of this study may provide the HEIs' decision makers valuable information about their respective internationalization processes to guide their strategic planning.

\section{FRAMEWORK}

Internationalization has increased asymmetrically among HEIs during the past decades and Altbach et al. (2007) noted that international activities have expanded in universities not only in terms of volume and scope, but also of complexity. International activities in the Philippines are varied and they range from the education and training of student and faculty abroad to internationalizing the curriculum, research collaboration and international networks (Bernardo, 2003; Gonzales, 2006; Karim and Maarof, 2013). International activities in HEIs are driven by the motives of internationalization. This section discusses the varied motives that propel HEIs in undertaking internationalization. It also explores on 
the different approaches to internationalization commonly undertaken by HEIs. The study likewise explores the impact of these approaches on the institution at the level of faculty and students.

Motives. HEIs must have a clear understanding of "why" internationalization is significant for the institution. A decisive motive should underlie the logic of a truly global academic institution which is not to teach the world but to learn from the world in order to enhance the institution's capacity to create new knowledge and develop truly global citizens (Hawawini, 2011). Knight (2004) and Stier (2004) identified categories of rationales or motives that drive HEIs to internationalize. These are academic (achieving international standards for both teaching and research); economic (finding new sources of revenues and growth); political (influencing potential and actual opinion leaders to enhance the political standing of the institution's country of origin); and religious (spreading the faith of a particular religious organization). This study focuses only on academic and economic motives since these are higher education institutions based where benefits from internationalization are more apparent. Academic internationalizing rationales goes by the reasoning that "by encouraging greater internationalization across teaching, research, and service activities, the quality of higher education can be enriched" (Ghasempoor et al., 2011). These are driven to fulfill the institution's educational mission; to remain academically relevant in an interconnected world that is becoming increasingly global and to attract the best students and faculty worldwide. With the current labor market requiring graduates to have international, foreign language and intercultural skills to be able to interact in a global setting, institutions are placing emphasis on internationalization. Another aspect to this reality is the competitive pressures from peer institutions that established international dimensions to their programs (Van der Wende, 2007; OECD, 2012; CHED, 2012).

Analyzing the HEIs motives to internationalize may start with its reason for being. Hill and Green (2008) suggest that questions like: "Is internationalization part of the vision, mission, or goals of the institution?" "Is internationalization needed to achieve its mission?" Beyond accomplishing one's mission through relevant programs and experiences for students are academic realities that HEIs need to address. For continuing relevance, the demand from stakeholders especially the faculty and students for courses, programs, and research topics that deal with global issues need to be appropriately addressed (Hill and Green, 2008; Iuspa, 2010). Iuspa (2010) likewise indicated that while the central role 
of the faculty could not be questioned in internationalization, students are also expecting an undergraduate education that will prepare them to be competitive in a more globalized world (Van der Wende, 2007; OECD, 2012; CHED, 2012). Motives to internationalize among institutions are basically academic if the drive is to achieve global standards to enrich the quality of higher education. To sustain this momentum also indicate the need for the steady support of the administration, budget and manpower to encourage greater internationalization across teaching, research and service activities.

Alongside the academic rationale is the economic motive of internationalization which is driven ultimately by a need to find new sources of revenues and growth. Altbach and Knight (2007) said that "earning money is a key motive for all internationalization projects in the for-profit sector and for some traditional nonprofit universities with financial problems." These authors claimed that many countries host new private universities with overseas links with some in the for-profit sector where international students are recruited to earn profits by charging high fees. In other cases, where enrollment in some programs drop as a result of changes in economic conditions or the supply has exceeded demands, offering a program abroad can shield revenues from these domestic sources of risk because revenues from educational markets around the world do not vary synchronously: countries are at different stages of economic and technological development and have different demographic profiles. These differences, in turn, produce different levels of demand for education around the world and create opportunities for HEIs for sources of revenue (Hawawini, 2011). Funding is crucial to the internationalization of higher education to sustain the academic motives. Even if the main motivation is not financial, the issue of internationalization's sustainability requires funds side by side with the constant commitment to succeed (Knight, 2007); hence, there is a need to invest in advanced internet networks to enable collaboration in research, provide access to specialized instrumentation and encourage collaboration for teaching and learning (OECD, 2012).

Furthermore, within the academic and economic motives are stakeholders that influence the HEIs' rationales for internationalization. Iuspa (2010) noted that within the institution there are three subgroups: "the institutional level, the academic and their departments, and the students" (de Wit, 2000, p. 12). These subgroups have their own motives for internationalization. As these subgroups interact, their motives may overlap leading to the internationalization process of the institution. 
In review, motives serve as the founding pillars of the internationalization process. Since these motives are not mutually exclusive, HEIs must have a clear understanding of "Why" internationalization is significant for the institution. Which rationales HEIs decide to follow, will depend on the institution's history, resources, and the stakeholders' influences (Iuspa, 2010).

Approaches. HEIs' motives for internationalization are evident in the practices and/ or processes also called approaches. An approach to internationalization reflects or characterizes the "values, priorities, and actions that are exhibited during the work towards implementing internationalization" (Knight, 2004). Identifying the institution's approach will assist the school in assessing its internationalization processes.

At the institutional level, Knight (2004) espoused six approaches to internationalization such as (a) activity (b) outcomes; (c) rationales; (d) process; (e) at home; and (f) abroad. Specifically, the activity approach covers study abroad, curriculum and academic programs, institutional linkages and networks, development projects, and branch campuses. The outcomes approach refers to desired outcomes such as student competencies, increased profile, more international agreements, and partners or projects. The rationales approach consists of the primary motivations of internationalization. In relation to the process approach, internationalization is considered a process where an international dimension is integrated into teaching, learning, and service functions of the institution. The At home approach understands internationalization as the creation of a culture or climate on campus that promotes and supports international/ intercultural understanding and focuses on campus-based activities. The Abroad (cross-border) approach refers to the cross-border delivery of education to other countries through a variety of delivery modes (face-to-face, distance, e-learning) and through different administrative arrangements (franchises, twinning, branch campuses, etc.).

Similarly, Bernardo (2003) reflected Knight's approaches to internationalization in his models of international higher education clustered into internationalism, and open market transnational education. Under internationalism, the activities encompass: (a) international student mobility, (b) faculty exchange and development, (c) research collaboration, (d) foreign language study, (e) building international perspectives, and (f) international networks. Examples of open market transnational education are: (a) distance education, (b) locally supported distance education, (c) twinning programs, (d) branch campuses, (e) franchising 
agreements, and (f) international quality assurance systems.

Three dimensions were identified by other authors as a component to academic mobility namely: student mobility, program mobility, and institution mobility (Do and Pham, 2014). First, student mobility denotes students' leaving their respective home countries to study in another country either through governmental scholarships or by self-finance mode. Second, program mobility entails joint degree programs through partnerships programs offered overseas by one institution or jointly by two or more. This program mobility comes through collaboration with foreign institutions either through franchising or twinning agreements.

Approaches to internationalization in this study discussed of activity; outcomes; process; at home; and abroad (Knight, 2004); internationalism, and open market transnational education (Bernardo, 2003) and student mobility, program mobility, and institution mobility (Do and Pham, 2014). Synthesizing what they espouse yields the following common approaches to internationalization namely: international student mobility (Bernardo, 2003; Knight, 2004; Do and Pham, 2014; Rudzki, 2000)); faculty exchange and development (Bernardo, 2003); institutional linkages, networks and research collaboration (Knight, 2004; Bernardo, 2003); and partnership programs or cross-border delivery of education to other countries through a variety of delivery modes using strategies such as face-toface, distance, and e-learning (Bernardo, 2003; Do and Pham, 2014); building international perspectives by having the international dimension integrated into teaching, learning and service functions (Bernardo, 2003; Knight, 2004). Models of Knight (2004), Bernardo (2003), and Do and Pham (2014) served as guide to analyze the motives, approaches, and impact of internationalization of the HEIs under study.

Crucial to the actualization of internationalization at the level of the HEI functions are the faculty. Iuspa (2010), however, indicated that while the central role of the faculty could not be questioned in internationalization, students also expect an undergraduate education that will prepare them to be competitive in a more globalized world (Van der Wende, 2007; OECD, 2012; CHED, 2012). Faculty and students understanding of internationalization in their institutions are central to the "process of integrating an international, intercultural and/or global dimension into the goals, function (teaching/learning, research, service) and delivery of higher education (Knight, 2003). It is, then, very important to assess their general attitudes to internationalization, their view of support for internationalization in the learning environment and their perceived benefits. 


\section{OBJECTIVES OF THE STUDY}

This study looked into the internationalization motives and processes of four selected HEIs in the country. It further studied their specific approaches to internationalization.

\section{METHODOLOGY}

This study was conducted in three universities and one college. Three HEIs were from Cagayan de Oro City (Xavier University, Liceo de Cagayan University and Lourdes College) and one from Manila (De La Salle University). A total of 928 randomly sampled college students, 150 faculty members, and 18 administrators were the sources of quantitative and qualitative data. From the three HEIs in Cagayan de Oro, the researchers agreed to limit their focus on the three colleges of their respective institutions (College of Arts, College of Business, and Teacher Education) while respondents from Manila were from the colleges of Engineering and Science only since the institution was on a special term owing to the institution's change in its academic calendar. These colleges were specifically chosen because of their "traditional" or established courses for the last fifty years at the least. Respondents of the study were the school administrators, faculty and students.

Table 1. Respondents of the Study

\begin{tabular}{|c|c|c|c|}
\hline HEI & Students & Faculty & Administrators \\
\hline A & 328 & 50 & 6 \\
\hline B & 362 & 44 & 6 \\
\hline C & 75 & 29 & 2 \\
\hline D & 165 & 27 & 4 \\
\hline Total & 928 & 150 & 18 \\
\hline
\end{tabular}

Table 1 shows the distribution of the respondents. Administrators included the deans, chairpersons, vice presidents (academics and finance), and internationalization officers.

The study used the concurrent mixed method research design where quantitative data were collected parallel to the gathering of qualitative information (Creswell, 2011) using the case study approach. The Student and Faculty Survey Questionnaires on Internationalization (Iuspa, 2010) was the main source of 
quantitative data and the Questions to Guide the Internationalization Review (Hill and Green, 2008) was the main source for the qualitative data. Specifically, the 29-item questionnaire sought the opinions of the respondents on their general attitude towards internationalization (items 1-12), perceived support for internationalization in the learning environment (items 13-19), benefits of internationalization (21-26), and three questions answerable with yes or no (2729). On the other hand, the questions to guide the Internationalization Review consisted of open-ended questions that included articulated commitment, strategy, structures, manpower, curriculum and co-curriculum, education abroad, analysis and recommendations. Quantitative data were analyzed separately from qualitative data. Results were compared and were combined.

To gather the qualitative data, focus group discussions, key informant interviews and individual interviews were utilized. Analysis of documents was utilized such as college reports, outcomes based curriculum and syllabi for each course offered in the colleges under review, to determine if graduate attributes, program/learning outcomes reflected internationalization. The researchers gathered data from their own HEIs to develop their case studies, after which the four individual cases were summarized into one presentation.

\section{RESULTS AND DISCUSSION}

Motives. HEIs recognized the need to respond earnestly to "a rapidly changing globalized world and be mindful of global competitiveness" (CHED, 2012) to sustain the institution's relevance. The present vision, mission and goals of HEIs under study, subtly or explicitly, emphasized enhancing the quality of education within the internationalization perspective. These are stated as "preparing global leaders" (LDCU, 2014), "forming leaders that serve the global community" (XU, 2014); "...that become global citizens, who think globally while acting locally" (DLSU, 2012) and "leaders in varied socio-cultural settings." (LC, 2013). For these HEIs, the VMG justify their processes and approaches to learn from the world and achieve international standards. Furthermore, such commitments to internationalization have permeated in the institutions' view of their graduates and of their program outcomes expressed in general as preparing students for global work. Specifically, these are exhibited as "globally competitive graduates"; "excellence through global standards" and globally responsible leaders" (HEI A); "man and woman of the 21 st century" and "a person committed to understanding of his/her self and of his/her duties ...to the world" (HEI B); "to attain global 
presence in scholarship and international engagement" (HEI C) and HEI $\mathrm{D}$, "engaging in lifelong learning .. keeping abreast with national and global development" are evidently articulated.

Institutional responses to globalization's challenges and opportunities also include the creation of offices that oversee internationalization concerns. For example, HEI A has the Office for External Relations and Internationalization manned by a Vice President and HEI B established an Office for International Networking and Cooperation since 2006. HEI C can trace its internationalization effort back in 1968, but it was in 1996 and 1997 when more academic linkages were put up to serve both faculty and student foreign exchange exposure of the university. In 2011, a fully dedicated internationalization office was established with two centers: The Global Engagement for academic relations and linkage programs and The International Center for global education and exchange programs, linkages with embassies, program development, service management and advisory for international students. Meanwhile, the organizational structure of HEI D provides an external affairs office. This is supported by the deans and the research, planning and development coordinators who are also entrusted the responsibility to engage in internationalization initiatives.

Currently, the economic motive for internationalization is also seen with the responsibility of the offices to obtain and increase development funding for internationally focused research initiatives. Nonetheless, all three HEIs (A, B, D) claimed that most internationalization initiatives, for now, are financed by the institution with the end view to be self- sustaining in the long run.

From the preceding discussions, the academic and economic motives of the University to internationalize are clear. Document analysis revealed that it is not only in the VMGs where the intention to internationalize is evident; these were also articulated in their respective graduate attributes as well as in the program outcomes. Establishing a formal structure to oversee internationalization activities further support the motive of the HEIs to internationalize. All these efforts of the HEIs go by the reasoning that "by encouraging greater internationalization across teaching, research and service activities, the quality of higher education can be enriched" (Ghasempoor et al., 2011).

Approaches. The four higher education institutions under study manifest similarities and variations of their approaches ranging from activity, outcomes, and processes and at home as espoused by Knight (2004). For activity, all the institutions highlight curricula and academic programs as well as networks and 
linkages. Other than embedding internationalization in the program of studies, and offering of foreign language studies, varied activities were launched by the four institutions. HEI A, in particular, forges partnerships with the Federal Republic of Germany through Goethe-Institut Philippinen under the PASCH program "Schools: Partners of the Future; HEI B links with the Association of Jesuit Colleges and Universities- Asia Pacific (AJCU-AP) Association of Jesuit Colleges and Universities in the Asia Pacific (AJCU- Asia Pacific), Goethe Institute (German), Instituto Cervantes (Spain), Japan Foundation (Japan), Alliance Francaise (French) and the French Embassy; HEI C networks with Gammasonic Institute for Research and Calibration of the University of Wollongong in Australia, Chung-ju National University, South Korea, California State University in Hayward, California, and Universidad La Salle, Mexico, Eindhoven University of Technology, Netherlands, National University, Singapore, Arkansas Tech University, USA, and Ritsumeikan University, Japan. In one hand, HEI D links with Intellectbase International Consortium in the publication of its research outputs, and St. John University in New York in the Dunn and Dunn Learning model. These linkages are geared toward upgrading the quality of higher education as espoused by Knight (2004) and Bernardo (2003).

The outcomes approach, likewise, in focusing on the desired outcomes such as but may not be limited to student competencies, increased profile, more international agreements, and partners or projects (Knight, 2004). These are reflected in the graduate attributes stemming from the respective HEIs' core values and program/course outcomes. Institutional linkages locally and abroad complement the development of student competencies encompassing their openness to cultural diversity. Around 28\% of students in HEI A and $10 \%$ students of HEI D engage in international internships which are currently limited to Southeast Asian countries and the United States. HEI B, in one hand, has provisions of fieldtrips abroad to supplement the "international" courses. HEI $\mathrm{C}$ reports on the presence and the opportunity of the inbound and outbound student exchange, as well as the visiting professors who have helped the university achieve some of its desired student attributes. For the school year 2013-2014 for example, the university was able to cater to 546 graduate international students and 235 undergraduate international students across the seven (7) colleges of the university. 
Meanwhile, internationalizing through the process approach is actualized through the integration of international dimensions into teaching, learning, research and service. All the HEIs under study embed international studies in their respective programs. HEIs A, C, and D for instance, have courses in the Arts college like 'International Relations Theories and Issues,' 'International Economics', 'World Civilization and Literature', "Introduction to Global Society" to name a few; HEIs B has $42 \%$ of its subjects with international content. HEI A, furthermore, is currently in research collaboration with the Chinese Academy of Sciences in China and had collaborations with the National University of Singapore; Singapore Botanic Gardens, and Chulalongkorn University. For HEI B, there is also evidence of faculty research collaboration with its counterparts abroad (CAS \& OICN, 2015). HEI D likewise engages in benchmarking in Asian institutions, research presentation in international fora, publication in international journals, and attendance of some faculty in international conferences.

The at home approach on the other hand, consists "of creation of a culture or climate on campus that promotes international/intercultural understanding and focuses on campus-based activities" (Knight, 2004). Cine Europa, the largest foreign film festival, is an offshoot of the partnership between HEI A and the European Union. For HEI B and C, international arts and culture are shown through films, exhibits and performances; the adaptation of Western classics in the context of Filipino reality. All four HEIs in this study engage in cocurricular activities such as cultural presentations; film shows, dance festivals, celebrations of international events; and international fora. HEI C further engages in International Center Buddy Pairing. Their international office facilitates welcome orientations for outbound and inbound students as reported earlier to almost a thousand graduate and undergraduate international students in the past school year.

The activities just discussed are corollary to the arguments that international activities in the Philippine HEIs under review are varied that ranged from the education and training of student and faculty abroad to internationalizing the curriculum, research collaboration and international networks (Bernardo, 2003; Gonzales, 2006; Karim and Maarof, 2013). To measure impact, Iuspa (2010) Survey Questionnaire was the main source of the data. 
Table 2. Combined Mean of the Mean from the

Attitude Survey Questionnaire (Scale of 1-4)

\begin{tabular}{|l|c|c|c|c|c|}
\hline \multirow{2}{*}{\multicolumn{1}{|c|}{ Impact Variable }} & \multicolumn{4}{c|}{ HEI } & \multirow{2}{*}{ Overall } \\
\cline { 2 - 5 } & $\mathrm{A}$ & $\mathrm{B}$ & $\mathrm{C}$ & $\mathrm{D}$ & ( \\
\hline General Attitude & 3.14 & 3.06 & 3.10 & 3.31 & 3.18 \\
\hline Support of learning environment & 2.96 & 2.78 & 3.05 & 3.10 & 2.97 \\
\hline Perceived Benefits of Internationalization & 3.38 & 3.24 & 3.54 & 3.46 & 3.41 \\
\hline
\end{tabular}

General Attitude. In all four HEIs, the faculty members were more aware of the University's direction towards internationalization as seen by their responses on "internationalization as a component of the strategic plan" and "university's mission-vision supporting internationalization." This was revealed by the facultyrespondents' mean scores which were generally higher than the students' mean scores. HEI A interviews revealed that students were unaware of the content of the strategic plan of the university. Some students further claimed they had not seen the restated vision, mission and goals of the University (FGD, July 27, 2015). Gleaned from a key informant, HEI B said that "since internationalization is a recently set goal of the university, its direction, efforts and results are not yet firmly evident" nonetheless, "it is undeniable that internationalization opportunities are also made available by the university for the faculty and the students" (Interviews, July, 2015). In an interview, for HEI C, only two out of ten students were aware of the internationalization mission found on the university webpage (FGD, July 28, 2015). Yet, there was a consistently high positive attitude on "foster internationalization of instruction, research, and service learning", "learning about people from different cultures is a very important part of education", "study abroad programs are the best way for students to encounter another culture" and "understanding of international issues is important for success in the workforce." However, both students and teachers of the four HEIs viewed "contact with individuals whose background differs from my own is not an essential part of education" rather low. It is said that some local students are not keen to interact with international students due to language, cultural or perceptual barriers (Jiang and Carpenter, 2014). This might be taken as a point of reflection by the entire community since this rating counters their core competence on "engender nurturing environment." In a nutshell, the general attitudes of respondents toward internationalization were fairly high implying favorable orientation of faculty and students toward responding to globalization. 
Support of Learning Environment. Both faculty and student's groups rated the items the lowest on the average of 2.97 for the four (4) HEIs. The support category had the lowest mean for both groups. It showed that communication and promotion of internationalization activities need enhancement (noted comments on survey, 2015). Generally, the respondents felt that "encouragement to study abroad, researching about international topics, attending international symposium/lectures in the campus or taking courses with internationalization were least perceived as a prominent support for integration into teaching, research and service.

Perceived Benefits. Perceived benefits of internationalization were rated highest among the three aspects of the survey (3.41). In HEI A, both groups regarded "international learning as a means to prepare for global citizenship and to appreciate other cultures" as highly beneficial. Students also generally expressed that among the many benefits gained from the three-month experience outside the country included enhancing their sense of independence, time and budget management, higher self-confidence, and respect for other culture. Many of them expressed their wish for their other classmates to also participate in similar experiences. Others said that "the OJT in US made me a better person because I have become more patient and understanding of other people;" and there were also "actual experiences learned where these were purely theoretical in our courses" (FGD, July 15, 2015). For HEI B and C, the item on "International education helps me recognize and understand the impact other cultures have on Filipino life and vice versa" was rated highly positive by both students and the teachers. One student wrote on his/her questionnaire that "my reflection on the how other culture works helped me value and appreciate our own culture." This reflects also the high rating on "the more we know about other countries, the better we will understand our own". This item was rated highly positive by teachers and students. A respondent teacher wrote "internationalization will help the individual appreciate other people-which include their way of life, their conduct of business, etc." On the other hand, HEI D students who experienced international practicum disclosed from key informant interviews (July 20,2015) that their encounter with different cultures enable them to practice independence, exercise greater responsibility, gain confidence in speaking English and feel affirmed of their good works and communication skills. These experiences enhance reflection, and enrich self-understanding among faculty and students (Stier, 2010). 


\section{CONCLUSIONS}

The discussions are evident of the conscious efforts of all HEIs in this study to give flesh to this commitment given the observed existing internationalization structure, policies, activities and processes. An analysis of the effect of these approaches shows that overall, students and faculty have positive attitudes toward internationalization. International learning, for both students and faculty, is relevant as an element of the educational process. Faculty and students are convinced that internationalization is highly beneficial to education. For the most part, not many faculty and students of the colleges under review have opportunities to experience these activities and processes. In the earlier discussion, it cited only a very small percentage of student mobility and very minimal faculty exchange and research collaboration because of funding constraints. Also, in the process approach, while there is a degree offered on internationalization, opportunities for other students in other courses are minimal since there were only few subjects in internationalization and globalization; other teachers likewise claimed to integrate global context in their lessons but they also admitted that these are oftentimes very sporadic. Believing in the potentials of international exposures for faculty and students learning experiences, institutions need to go back to the drawing board and map out strategies to maximize faculty and student internationalization activities, processes and other related approaches in response to its commitment on internationalization. Likewise, the issue of revenue generation to sustain the commitment of preparing global leaders as reflected in the VMG has to be intently considered by the HEIs involved in this study.

\section{LITERATURE CITED}

Altbach, P. G., \& Knight, J. (2007). The internationalization of higher education: Motivations and realities. Journal of studies in international education, 11(3-4), 290-305. http://www.uni-kassel.de/ wz1/mahe/course/ module6_3/01_altbach07.pdf

Bartell, M. (2003). Internationalization of universities: A university culturebased framework. Higher Education. (45)1, 43-70 https://scholar. google.com.ph/scholar?q=bartell $+2003 \& b t n G=\& h l=e n \& a s \_s d t=$ $0 \% 2 \mathrm{C} 5$ 
Bernardo (2003). in Tullao, T. S. (ed) Education \& globalization (pp. 213-272) Philippine APEC Study Center Network. Retrieved July, 2015 @ http://dirp4.pids.gov.ph/ris/books/pidsbk03-education.pdf

Bond, S. (2006). Transforming the culture of learning: Evoking the international dimension in Canadian university curriculum. http://international. yorku.ca/global/conference/canada/papers/Sheryl-Bond.pdf

Chan, W. \& Dimmock, C. (2008). The internationalization of universities Globalist, internationalist and translocalist models. Journal of Research in International Education, 7(2), 184-204. Abstract retrieved July 20, 2015, from Sage Journals database.

CHED (2012). Policy-standard to enhance quality assurance (QA) in Philippine Higher Education through an Outcomes-based and typology-based QA. Retrieved from http://www.ched.gov.ph/wp-content/uploads /2013/07/CMO-No.46-s2012.pdf

Creswell, J. W. (2011). Controversies in mixed methods research. The Sage handbook of qualitative research, 4, 269-284.

De La Salle University. (2014). External Relations and Internationalization Office. Retrieved from http://www.dlsu.edu.ph/offices/evperi/default. asp

De Wit, H. (2010). Internationalisation of higher education in Europe and its assessment, trends and issues. Netherlands: Nederlands-Vlaamse Accreditatieorganisatie http://www.obiret-iesalc.udg.mx/sites/default /files/adjuntos/internationalisation_of_higher_education_in_europe_ de_wit.pdf

Do, T. T., \& Pham, D. N. (2014). Academic Mobility in South East Asia: Challenges and Opportunities in the Coming Decades. International Education, 44(1), 28. http://search.proquest.com/docview/16363580 70 ?accountid $=28547$ 
Elkin, G., Farnsorth, J., \& Tempier, A. (2008). Strategy and the internationalisation of universities. International Journal of Educational Management, 22 (3), 239-250.

Ghasempoor, A., Liaghatdar, M. J., \& Jafari, E. (2011). The internationalisation of higher education: An effective approach for Iran higher education. Higher Education Studies, http://www.ccsenet.org/journal/index.php/ hes/article/view/13280/9146

Gonzales, A. (2006). The Philippines. (Ed.) Higher Education in South-East Asia (pp. 137 - 158) Bangkok: UNESCO Asia and Pacific Regional Bureau for Education.

Haigh, M. (2008). Internationalization, planetary citizenship and higher education Inc. Compare, 38(4), 427-440.

Hawawini, G. (2011). The internationalization of higher education institutions: A critical review and a radical proposal. Social Science Research Network. doi: $10.2139 /$ ssrn. 1954697

Hénard, F., Diamond, L., \& Roseveare, D. (2012). Approaches to internationalisation and their implications for strategic management and institutional practice. 2013-03-20). www. oecd.org/edu/imhe/ Approaches 20to 20internationalisation: 20-M 20 final: 20-20web. pdf. Retrieved July, 2015 from http://search.oecd.org/edu/imhe/ Approaches\%20to\%20internationalisation $\% 20 \mathrm{final} \%$.pdf

Hill, B. A., \& Green, M. F. (2008). A guide to internationalization for chief academic officers. American Council on Education.

Iuspa, F. E. (2010). Assessing the effectiveness of the internationalization process in higher education institutions: A case study of Florida International University. http://search.proquest.com/docview/858857253?accountid $=28547$ 
Jiang, N., \& Carpenter, V. (2014). A case study of emerging challenges and reflections on internationalization of higher education. International Education Studies, 7(9), p56.

Karim, F. \& Maroof (2013). Towards understanding the internationalization of higher education and its challenges. Internationalizing higher education in Malaysia: Understanding, practices and challenges. Singapore: Institute of Southeast Asian studies.

Knight, J. (2004). Internationalization remodeled: Definition, approaches, and rationales. Journal of studies in international education, 8(1), 5-31. https://tru.ca/_shared/assets/Internationalization-Remodeled29349. pdf

Marsella, A.J. (2001), "Essay: Internationalizing the psychology curriculum", Psychology International, Vol. 12, No. 2, pp. 7-8

Misra, S., \& Bajpai, A. (2011). Implications of globalization on education. Rochester: Social Science Research Network. doi:10.2139/ssrn. 1800740

Nimomiya, A., Knight, J. \& Watanabe, A (2009). The past, present, and future of internationalization in Japan. Journal of Studies in International Education, 13(2), 117-124. Abstract retrieved July 20, 2015, from Sage Journals database.

Pama, R. P. (2012). The role of education in the pursuit of globalization and internationalization. In Seminar on Leveling Up to ASEAN 2015. Building Linkages and Securing Grants (pp. 22-23).

OECD (2012). Global knowledge flows and economic development. Retrieved from http://www.oecd.org/leed-forum/publications/Global\%20 Knowledge\%20Flows\%20and\%20Economic\%20Development.

Rudzki, R. E. (2000). Implementing internationalization: The practical application of the fractal process model. Journal of Studies in International Education, 4(2), 77-90. 
Sporn, Barbara (1999). Adaptive university structures: An analysis of adaptation to socioeconomic environments of US and European universities. Higher Education Policy Series 54. Philadelphia: Taylor and Francis, Inc.

Stier, J. (2004). Taking a critical stance toward internationalization ideologies in higher education: Idealism, instrumentalism and educationalism. Globalization, Societies and Education, 2 (1),1-28.

Van der Wende, M. (2007). Internationalization of higher education in the OECD Countries: Challenges and Opportunities for the Coming Decade. Journal of studies in international education. 11(2-3), 274-289. Abstract retrieved July 20, 2015, Sage Journals 